\title{
Recruitment of polychaetes and bivalves: long-term assessment of predictability in a soft-bottom habitat*
}

\author{
Robert J. Feller ${ }^{1,2,3}$, Stephen E. Stancyk ${ }^{1,2,3}$, Bruce C. Coull ${ }^{1,2,3}$, \\ Donald G. Edwards $s^{3,4}$ \\ ${ }^{1}$ Dept of Biological Sciences, ${ }^{2}$ Marine Science Program, ${ }^{3}$ Belle W. Baruch Institute for Marine Biology and Coastal \\ Research, ${ }^{4}$ Dept of Statistics, University of South Carolina, Columbia, South Carolina 29208, USA
}

\begin{abstract}
A 5 yr record (1981 to 1985) of polychaete and bivalve abundance in North Inlet, South Carolina, USA, was examined to estimate whether the timing of peaks in abundance of planktonic larvae was a reliable predictor of settlement timing and abundance of meiobenthic and macrobenthic recruits. Biweekly collections of zooplanktonic larvae, meiobenthos, and macrobenthos were made in close proximity to each other. Both smoothing and regression techniques were used to characterize the recruitment patterns of each life-history category. Despite year-to-year variability in both estimated peak abundance and the time of the peak's appearance, an annual cycle in the pattern for these major taxa was apparent. The interval between appearance of planktonic larval peaks and subsequent peaks in abundance of meiobenthos and macrobenthos varied greatly during 5 years. We conclude that, despite variability in the timing of settlement and recruitment of soft-bottom benthos, the temporal windows during which recruitment activity is highest are very predictable for polychaetes and bivalves in North Inlet. This will allow more efficient investigation of these fundamental events with higher frequency samplings in the future. The stock-recruitment problem, a lack of predictable correspondence between planktonic larval and adult abundances, is no less complex in benthic ecology than in fisheries ecology
\end{abstract}

\section{INTRODUCTION}

The timing and strength of recruitment of benthic invertebrates from the plankton into soft-bottom habitats is unpredictable. Attempts to predict settlement or year class strength of macrobenthos from observations of larvae in the plankton generally have not been successful because the transition is complex and affected by many variables (Luckenbach 1984, Hadfield 1986, Butman 1987). Although Luckenbach (1984) pointed out that recruitment actually involves 2 phases, settlement from the plankton to the bottom and early post-larval survival, investigators of softbottom macrobenthos typically have not made this distinction. An operational definition of recruitment for macrobenthos includes settlement followed by post-larval survival and growth to a size capable of - Contribution No. 957 from the Belle W. Baruch Institute for
Marine Biology and Coastal Research retention on a $0.5 \mathrm{~mm}$ sieve, the mesh size traditionally used to collect the smallest macrobenthic organisms in shallow water.

The transition between habitats prior to attaining macrofaunal size includes many important but poorlyknown events in the life histories of larvae and juveniles (Hadfield 1986, Woodin 1986, Morse 1991). Without sampling the transition phase, benthic ecologists have a diminished understanding of the relationships between larval planktonic and adult benthic populations of macrofauna. In particular, a definition of recruitment occurring at $0.5 \mathrm{~mm}$ has equivocated interpretation of, or masked, the timing (pulsed or regular, early or late) and spatial variation of settlement (Gaines et al. 1985, Yoshioka 1986, Young 1989), specific periods of high mortality (Strathmann \& Branscomb 1979, Bell \& Coull 1980, Luckenbach 1984. Connell 1985), correlations between planktonic and macrobenthic abundances (Stancyk \& Feller 1986, Roughgarden et al. 1988) and estimation of post- 
settlement growth rates (Highsmith \& Emlet 1986). An understanding of these recruitment events requires intensive study at small spatio-temporal scales as well as knowledge of a variety of environmental variables and solution of several methodological problems (Hadfield 1986). Whether predictions about the timing and magnitude of adult soft-bottom macrobenthic populations can ever be made from quantitative plankton samples remains an open question.

As part of the ongoing Long-Term Ecological Research (LTER) project (Callahan 1984, Franklin et al. 1990, Magnuson \& Bowser 1990), we have been collecting nearly-synoptic samples of zooplankton, meiobenthos, and macrobenthos every $2 \mathrm{wk}$ in the North Inlet estuary since January 1981. Thus, we have a quantitative record for 3 life-history categories of potential recruits: planktonic larvae, recently settled rccruits (meiobenthos), and larger individuals (macrobenthos) of several taxa over time. We are unaware of similar data sets of this length which include all 3 categories of benthic, soft-bottom invertebrate taxa with pelagic larvae. This quantitative data set presents a unique opportunity to link the transitional life-history phases of some common invertebrate taxa. We have used the first 5 years of the LTER faunal data (1981 to 1985) to address the following, taxon-level, questions for polychaetes and bivalves:

- When do peaks of abundance occur?

- Are peaks of planktonic larval abundance followed by peaks first in the meiobenthos and then in the macrobenthos?

- Is the timing of the peaks in each sampling category predictable, or is the interval between peaks variable?

- Does the abundance of larvae in the plankton predict the strength of recruitment to the meiobenthos and/or the macrobenthos?

- Which transition phase, zooplanktonic to meiobenthic or meiobenthic to macrobenthic, exhibits the greatest mortality?

Our purpose is, therefore, 2-fold: to answer these questions where possible and to present an objective, quantitative approach to the analysis of patterns in our recruitment data using regression techniques. We view this as a valuable enhancement to an otherwise subjective, qualitative interpretation of temporal changes in abundance of the planktonic and benthic life-history phases of these 2 globally important faunal groups.

\section{METHODS AND MATERIALS}

Study site. North Inlet, South Carolina, USA $\left(33^{\circ}\right.$ $\left.20^{\prime} \mathrm{N}, 79^{\circ} 10^{\prime} \mathrm{W}\right)$, is a hydrographically complex estuarine system (3200 ha) consisting of numerous tidal creeks (22\% of area) and saltmarsh vegetation, chiefly Spartina alterniflora $(70 \%)$. It is well-mixed and has a mean semidiurnal tide range of $1.6 \mathrm{~m}$. Mean water depth of the major tidal creeks is $3 \mathrm{~m}$ (maximum $8 \mathrm{~m}$ ), water velocities seldom exceed $2.3 \mathrm{~m} \mathrm{~s}^{-1}$, and water exchange takes place via Town Creek with the Atlantic Ocean through the mouth of North Inlet about $2.5 \mathrm{~km}$ from the collection sites (Kjerfve et al. 1991).

Field sampling. For zooplankton, a site in Town Creek within $200 \mathrm{~m}$ of the mouth of Bread and Butter Creek was sampled every 2 wk from January 1981 to December 1985 ( $n=130$ dates). Zooplankton were sampled with paired, sequential $153 \mu \mathrm{m}$ closing nets with flow meters mounted in the center of the mouth opening. Both nets were deployed from a stationary boat during peak ebb tide velocity about $1 \mathrm{~h}$ before daytime slack low water. Closed nets were lowered to near the bottom (maximum depth $=4 \mathrm{~m}$ ) and opened by messenger. The nets were fished for $1 \mathrm{~min}$ at depth. raised half the distance to the surface and fished for another minute, and then raised to just beneath the surface for a final minute. A minimum of $1 \mathrm{~m}^{3}$ of water was filtered in this manner. Upon retrieval, net contents were transferred from the cod end to storage jars, stained with Rose Bengal and fixed in a $10 \%$ formalin + seawater mixture.

Meiofauna were collected subtidally about $100 \mathrm{~m}$ inside the mouth of Bread and Butter Creek by taking 2 replicate $5.32 \mathrm{~cm}^{2}$ cores to the depth of the redox layer (usually 1 to $2 \mathrm{~cm}$ ) at the long-term muddy site discussed by Coull (1985). Each core was extruded and immediately fixed in $10 \%$ buffered formalin with Rose Bengal.

Macrobenthic fauna were collected subtidally within $50 \mathrm{~m}$ of the meiofaunal collection site by taking 2 replicate $141 \mathrm{~cm}^{2}$ cores $15 \mathrm{~cm}$ deep (from 1981 to 1984) and 8 replicate cores $\left(18.1 \mathrm{~cm}^{2}, 0\right.$ to $5 \mathrm{~cm}$ ) in 1985 (Service \& Feller 1992). Each sample was extruded and fixed in $10 \%$ buffered formalin with Rose Bengal. Data for only the 0 to $5 \mathrm{~cm}$ segment of the larger core were used in this analysis.

Laboratory analysis. After each zooplankton sample was brought up to $200 \mathrm{ml}, 2 \mathrm{ml}$ Stemple pipette subsamples were taken ( 2 replicates with replacement) and all organisms counted to major taxon. Counts were adjusted to number per $\mathrm{m}^{3}$ according to volume filtered. The number of individuals per $\mathrm{m}^{2}$ was calculated by multiplying number per $\mathrm{m}^{3}$ by the average depth of the water column at the time of sampling. Each meiofaunal core sample was extracted using Ludox centrifugation (de Jonge \& Bouwman 1977). All animals passing through a $0.500 \mathrm{~mm}$ mesh but retained on a $0.063 \mathrm{~mm}$ sieve were counted to major taxon. Macrofauna were extracted by gently washing preserved samples through a $0.500 \mathrm{~mm}$ sieve. All 
organisms retained were identified to major taxon, which included polychaetes and bivalves.

The biota. Polychaetes (86 spp.) seasonally comprise from 30 to $90 \%$ and bivalves (probably 5 to 10 spp.) 5 to $25 \%$ of the macrobenthos at the muddy subtidal study site; numerically dominant polychaetes include Streblospio benedicti, Heteromastus filiformis, Mediomastus ambiseta, and several others from the families Nereidae, Lumbrinereidae, Cirratulidae, and Orbiniidae (Service \& Feller 1992). The dominant infaunal bivalves include species in the genera Mercenaria, Mulinia, Tellina, and Tagelus. Although oysters Crassostrea virginica are common in North Inlet, their larval abundance does not exceed 520 per $\mathrm{m}^{3}$ (mean $=62.7, \mathrm{SE}=12.6$, range $=0$ to $520, \mathrm{n}=76$ dates over 2 yr) at any time in the plankton (M. Crosby pers. comm.). Hence they are always a minor component of the zooplankton and should not affect estimates of abundance of bivalves dwelling on soft-bottom substrate. Although it is possible to identify the plank tonic larval stages of polychaetes and bivalves, especially in species-poor habitats, the large number of species in North Inlet has prohibited their routine identification. We are thus unable to address specieslevel questions in this particular data set. Nevertheless, patterns at the class level are sufficiently clear that they allow us to identify major recruitment events within each of the 3 life-history categories, and the types of questions asked are applicable to many other taxonomic levels.

Data analyses. Plots of standardized counts of polychaete and bivalve taxa (Figs. 1 \& 2 respectively) show alternating periods of growth and decline in mean abundance. Because the standard error bars in these figures show that variability in abundance increases with mean abundance, data were transformed following the method of Box \& Cox (1964). All formal analyses were carried out on the dependent variable $\log _{10}$ (standardized taxon count +1 ), averaged by date (for simplicity and to defuse issues of pseudoreplication)

Although these data form a time series, we have not performed standard time series analyses because these are relatively short series given their strong year-to-year variability. Five years are not sufficient to draw general conclusions on the underlying, strongly seasonal, processes. Instead, we have taken a regression approach, estimating the true mean abundance as a function of time. This approach allows examination of patterns in these 5 years, a natural and necessary first step before generalizing. Results of classical time series analyses on a longer time series of these data will be addressed elsewhere; however, spectral analysis of an 11 yr segment of data for total meiobenthos and of a 4 yr segment for macrobenthic poly- chaetes revealed only a 1 yr, statistically repeatable, cycle (Coull 1986).

The choice of regression function was dictated by both theoretical and empirical considerations. Exponential growth/decline in taxon counts is expected theoretically according to the relation $N_{t}=N_{0} \mathrm{e}^{g t}$, where $N_{t}$ is abundance at time $t$ (measured in days), and $g$ is a rate constant for the daily rate of change of abundance. This relation translates to linear increase and decrease in log abundance. To verify this empirically, a nonparametric regression function (MCDonald \& Owen 1986) was fit to the log-transformed means, with results shown by the smooth curves in Figs. 3 \& 4 . The McDonald-Owen algorithm was used because of its capability of detecting sharp changes in the function, while many other algorithms (e.g. running averages) might smooth these out. The McDonald-Owen smooths generally support the expectation that $\log$ abundance alternately increases and decreases in an approximately linear fashion for these taxa. This, then, effectively eliminated the uncertainty involved in trying to decide, subjectively, whether the few peaks defined by only one data point are true peaks of abundance.

Subsequent analyses were therefore based on quadratic spline (piecewise linear) regression functions, with least squares fits shown by the dotted lines in Figs. $3 \& 4$. For a comprehensive discussion of spline regression, see Wahba (1990). Connecting points ('knots') of the straight line seqments, which correspond to start dates of growth and decline seasons, and mean log-abundances at these dates were estimated by nonlinear least squares using the Statistical Analysis System's NLIN procedure (SAS 1985). These estimates and their covariance matrices were then transferred to the MATRIX procedure, where standard interval estimation using the $t$-distribution and hypothesis testing via F-tests analogous to the general linear model were applied (Chap. 1, Gallant 1987). Targets for estimation (Tables 1, 2 \& 4) and testing (Table 3) included start dates of growth and decline seasons, geometric mean abundance at these dates, growth/decline rates [i.e. the rate constant $(g)$ for each growth/decline season] and the length of intervals between minima and maxima.

Assumptions of the statistical analyses were checked using residual plots and tests, with no serious violations found. In particular, there were no substantial correlations in residuals between series (concurrently) or within series (across time). A small but statistically significant negative autocorrelation (on the order of -0.2 ) occurred in several of the series at lag 3 , corresponding to $6 \mathrm{wk}$. These are intriguing but so small as to be negligible with regard to the inferences outlined above. An interpretational note: judging from 
the sizes of standard errors, some estimates are considerably more accurate than others. The generally large standard errors are attributable in part to substantial unexplained variability about the fitted regression functions. However, global $F$-tests for significance of each regression were highly significant $(p<$ 0.001). In nonlinear regression, the accuracy with which an unknown is estimated depends in part on its true value and also on the values of other unknowns. This could explain the fact that some estimates have much higher standard errors than others. Ecological interpretation of the results should focus primarily on well-estimated quantities, i.e. those with small standard errors.

\section{RESULTS}

\section{Polychaetes}

There was a major peak in planktonic polychaete larvae during late summer of each year which preceeded a peak in meiofaunal polychaetes (Fig. 1). In 1981, 1984, and 1985, there were additional fallwinter peaks which were not followed by peaks in the meiofauna. The macrofaunal polychaete peaks generally occurred at about the same time or 2 wk after the meiofaunal peaks (Fig. 1). The interval between peaks of abundance was most regular in the macrobenthos, with peaks usually occurring in the late win-

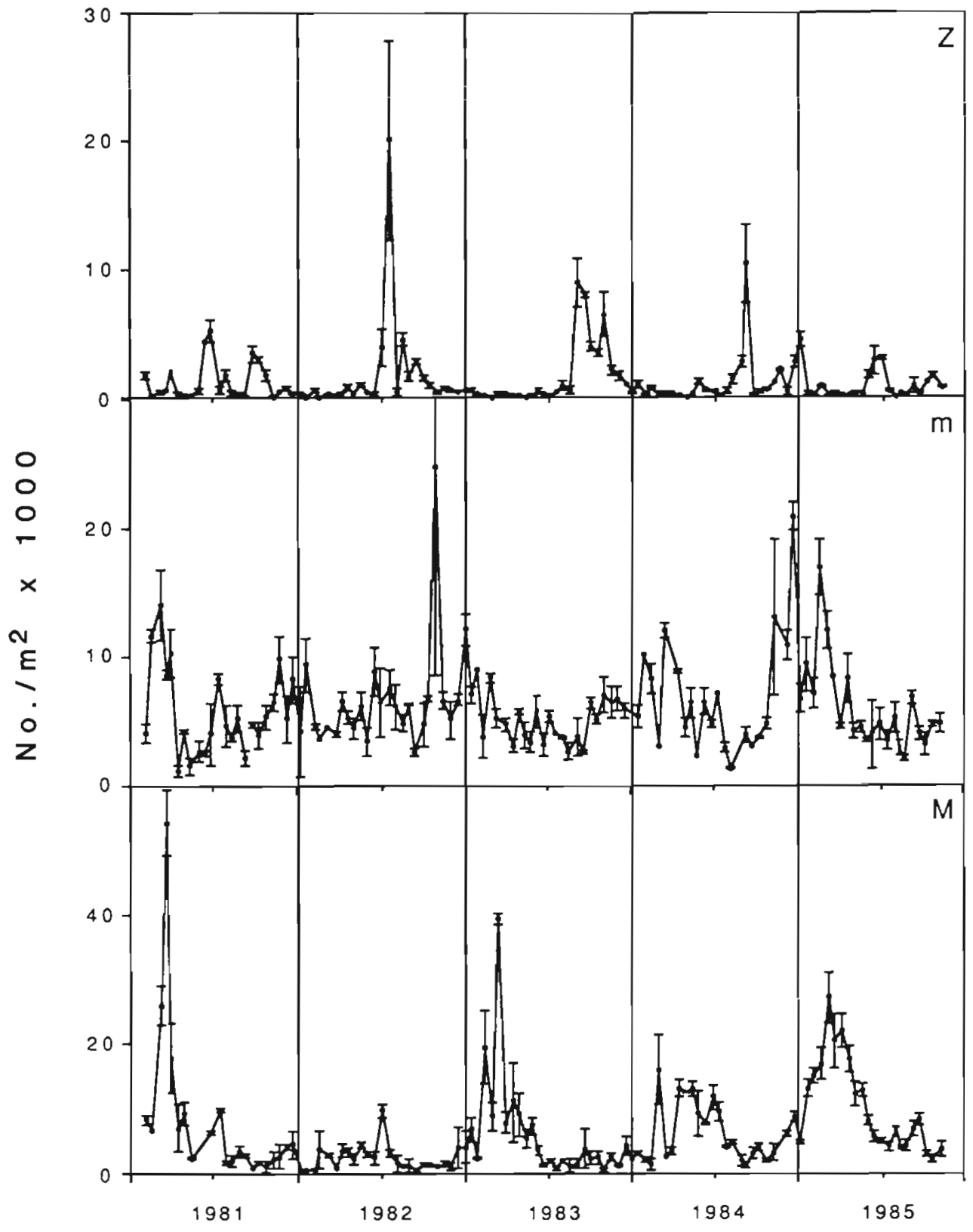

Fig. 1. Mean abundance (no. $\left.\mathrm{m}^{-2} \times 10^{3}\right)$ for zooplanktonic $(Z)$ merobenthic (m), and macrobenthic (M) polychaetes sampled biweekly from 1981 through 1985. Vertical bars represent \pm 1 SE 
ter or early spring. The second year of the time series, 1982, was unusual because there was no macrobenthos peak, and the peak in 1984 was only about half normal size despite typical abundances in the zooplankton and meiobenthos in both of those years (Fig. 1). The lags between appearance of peak numbers in the plankton and the meiobenthos and between the plankton and the macrobenthos were both approximately 5 to 6 mo. Planktonic polychaete larvae were present for periods of at least a month, and levels of abundance were quite similar from year to year in all 3 categories, except for 1982 and 1984 as noted above.

\section{Bivalves}

Compared to the polychaetes, bivalve recruitment was characterized by abundance peaks of shorter duration in the planktonic stage, greater year-to-year variability in all 3 categories, and shorter lags between peaks from category to category (Fig. 2). Minor or secondary peaks in the plankton $(1981,1983$, and 1984) and in the meiobenthos (1982 and 1983) were not followed by identifiable peaks in the succeeding categories. In the winter of 1984, the meiofaunal bivalve peak preceeded the planktonic larval bivalve peak by about a month (Fig. 2). Planktonic bivalves were most
Fig. 2. Mean abundance (no. $\mathrm{m}^{-2}$ $\times 10^{3}$ ) for zooplanktonic (Z), meiobenthic $(\mathrm{m})$, and macrobenthic (M) bivalves sampled biweekly from 1981 through 1985. Vertical bars represent $\pm 1 \mathrm{SE}$

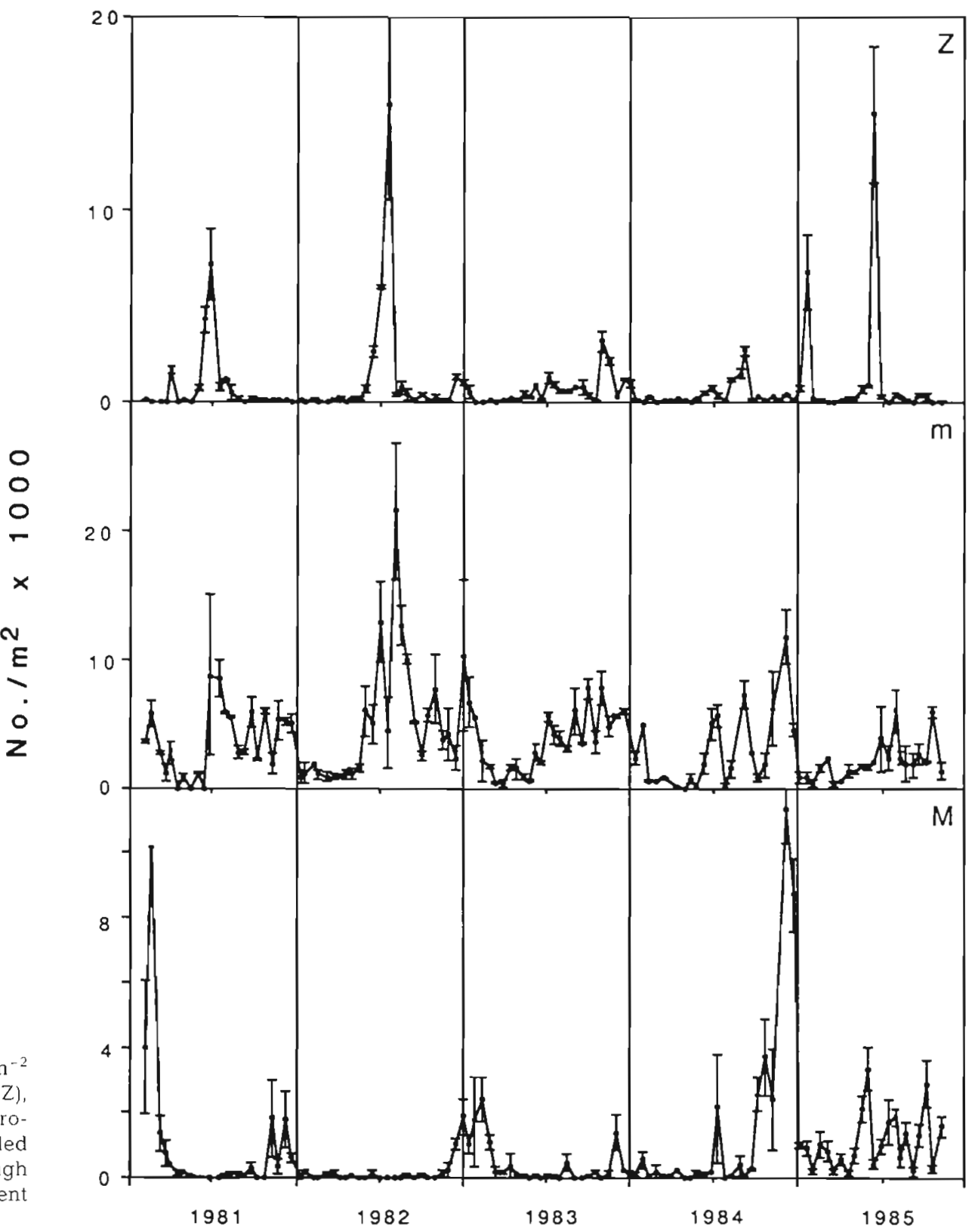


Table 1. Estimated knot dates and quantitative estimates of polychaete maxima and minima (\#; geometric mean no. $\mathrm{m}^{-2}$ ), estimated duration (in days) of growth and decline phases $(d)$, and an estimate of the daily rate of change of abundance $(g)$ for the mixed-species taxon in each life-history category. Dates correspond to knot dates in Fig. 3 . Values in parentheses are $95 \%$ confidence limits, which for dates and durations are \pm factors (in days) and for abundances are a factor for multiplying or dividing the mean

\begin{tabular}{|c|c|c|c|c|c|c|c|c|c|c|c|c|c|c|c|}
\hline \multicolumn{4}{|c|}{ Maximum } & \multicolumn{4}{|c|}{ Minimum } & \multicolumn{4}{|c|}{ Growth phase } & \multicolumn{4}{|c|}{ Decline phase } \\
\hline Date & $(\mathrm{CI})$ & \# & $(\times / \div)$ & Date & (CI) & $\#$ & $(\times / \div)$ & $d$ & (Cl) & $g$ & (Cl) & $d$ & (CI) & $g$ & (Cl) \\
\hline \multicolumn{16}{|c|}{ Planktonic larvae } \\
\hline 29 Oct 1981 & (144) & 710 & $(2.29)$ & 26 Feb 1982 & $(82)$ & 63 & $(1.57)$ & - & - & - & - & 120 & $(174)$ & -0.0201 & $(.039)$ \\
\hline $19 \mathrm{Jul} 1982$ & (38) & 3435 & $(1.64)$ & 26 May 1983 & $\{41\}$ & 50 & $(2.10)$ & 144 & (101) & 0.0278 & $(.017)$ & 311 & (45) & -0.0136 & $(.004)$ \\
\hline 26 Sep 1983 & (40) & 6807 & $(1.72)$ & 4 May 1984 & (49) & 53 & $(1.56)$ & 123 & (67) & 0.0400 & $(.010)$ & 220 & (70) & -0.0221 & $(.010)$ \\
\hline 22 Aug 1984 & (75) & 1700 & $(1.59)$ & $23 \operatorname{Mar} 1985$ & $(1102)$ & 332 & $(1.81)$ & 110 & $(100)$ & 0.0315 & $(.033)$ & 213 & (1104) & -0.0076 & (.034) \\
\hline \multirow{2}{*}{\multicolumn{4}{|c|}{ Meiobenthic juveniles }} & & & & & & & & & & & & \\
\hline & & & & 9 May 1981 & $(41)$ & 2557 & $(1.53)$ & - & - & - & & - & - & - & - \\
\hline 13 Nov 1981 & $(97)$ & 6059 & $(1.68)$ & 5 Feb 1982 & (213) & 4404 & $(1.53)$ & 187 & (99) & 0.0046 & $(.004)$ & 84 & $(280)$ & -0.0038 & $(.019)$ \\
\hline 3 Dec 1982 & (138) & 7286 & $(1.36)$ & 15 Jul 1983 & (121) & 3485 & (1.39) & 301 & $(277)$ & 0.0017 & $(.002)$ & 223 & (209) & -0.0033 & $(.003)$ \\
\hline 14 Feb 1984 & (108) & 7496 & $(1.44)$ & 20 Aug 1984 & $(60)$ & 3131 & $(1.52)$ & 214 & (193) & 0.0101 & $(.004)$ & 188 & (137) & -0.0046 & $(.005)$ \\
\hline $18 \mathrm{Jan} 1985$ & $(50)$ & 12026 & $(1.45)$ & 14 Aug 1985 & (83) & 2920 & $(1.74)$ & 151 & (89) & 0.0089 & $(.006)$ & 208 & (103) & -0.0068 & $(.004)$ \\
\hline \multicolumn{4}{|c|}{ Macrobenthos } & 23 Jan 1982 & & & & & & & & & & & - \\
\hline 2 Jul 1982 & $(50)$ & 5330 & $(2.29)$ & 7 Sep 1982 & (33) & 495 & $(2.10)$ & 159 & $(72)$ & 0.0118 & $(.009)$ & 67 & $(77)$ & -0.0355 & $(.053)$ \\
\hline 18 Mar 1983 & (34) & 14351 & (1.64) & 1 Sep 1983 & (43) & 1009 & $(1.56)$ & 192 & (52) & 0.0175 & $(.006)$ & 167 & (63) & -0.0159 & $(.008)$ \\
\hline 28 Jun 1984 & (39) & 10925 & $(1.72)$ & $6 \operatorname{Sep} 1984$ & (35) & 1491 & (1.81) & 300 & (64) & 0.0079 & $(.003)$ & 70 & (65) & -0.0285 & $(.033)$ \\
\hline 6 Mar 1985 & (38) & 21788 & $(1.59)$ & - & - & - & - & 181 & (56) & 0.0148 & $(.006)$ & - & - & - & - \\
\hline
\end{tabular}

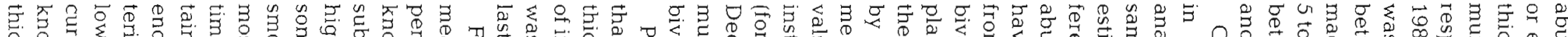

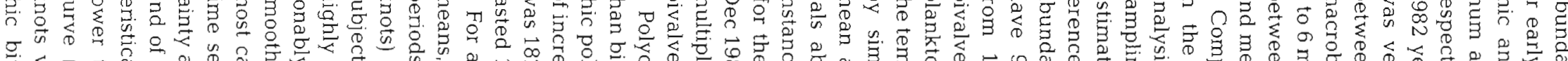

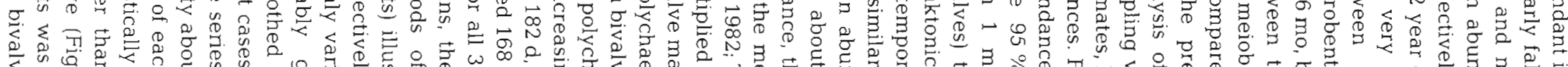

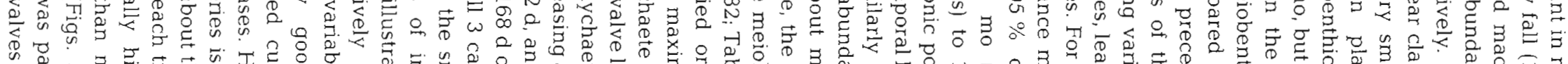

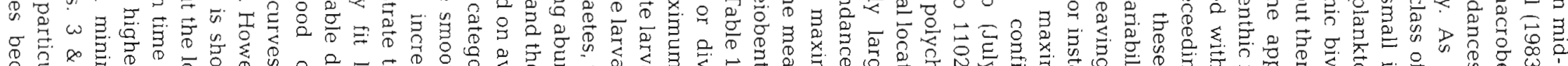

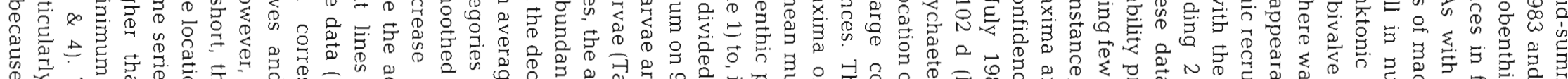

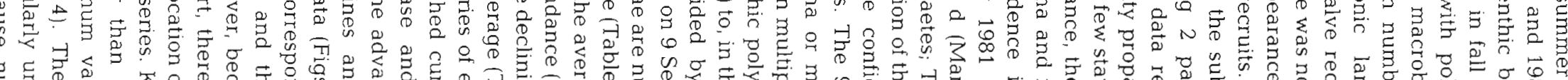

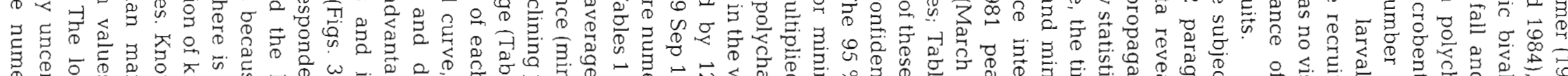

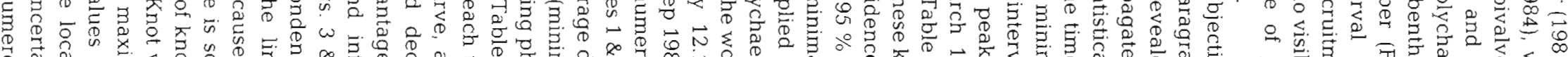

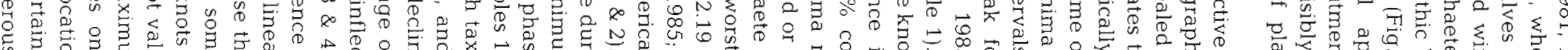

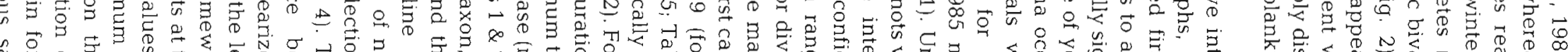

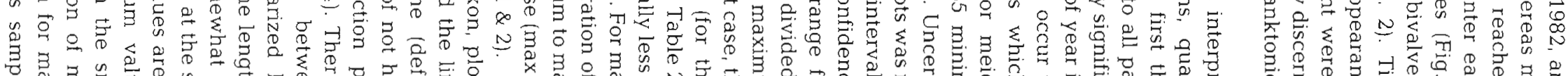

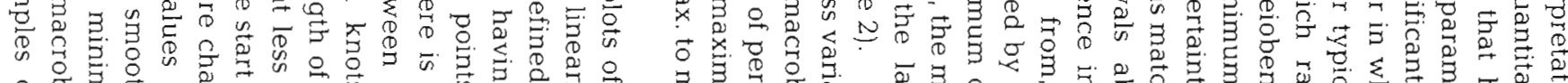
等

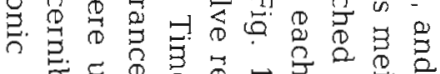

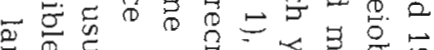

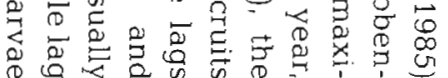




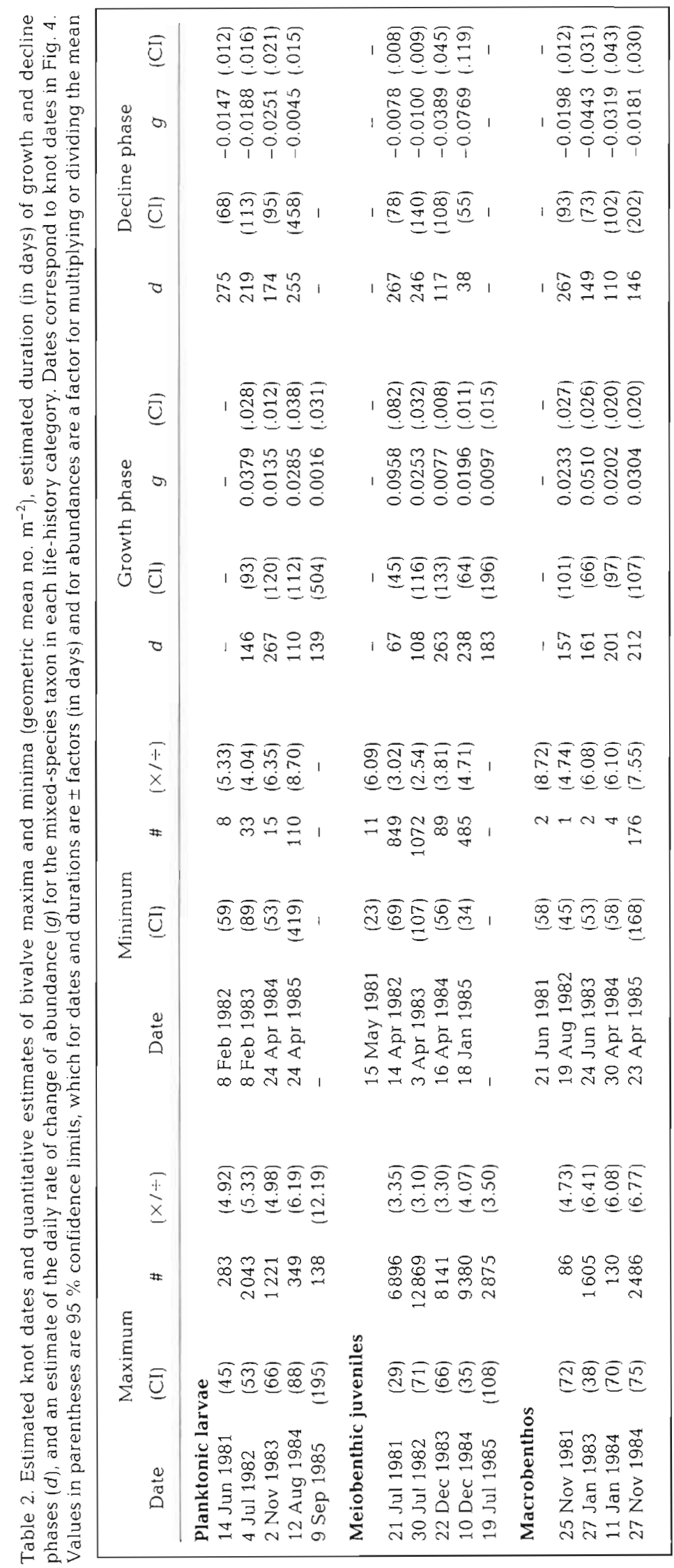

tained no animals (Fig. 4). Significant differences in the time of year that knots occur within categories (e.g macrobenthic polychaetes and meiobenthic bivalves) were detected (Table 3). However, there were no significant differences in minimum abundances of polychaetes through time within any category. The 2 benthic bivalve categories had significant differences among years in both their objectively defined maxima and minima (Table 3).

Time intervals between peaks of larval abundance in the plankton and the appearance of peaks in the meiobenthic and macrobenthic categories are consistent with an annual periodicity, but there are large differences from year to year in all transitional phases, whether from zooplankton to meiobenthos $(\mathrm{Z} \rightarrow \mathrm{m})$ or from meiobenthos to macrobenthos $(\mathrm{m} \rightarrow \mathrm{M})$ (Table 4). For example, the interval between the larval polychaete peak and the meiobenthic polychaete peak ranged from $14 \mathrm{~d}$ in 1981 to $150 \mathrm{~d}$ in 1984-85. Similarly wide-ranging intervals occurred for the transition between meiobenthic and macrobenthic bivalve minima: $13 \mathrm{~d}$ in 1984 to $127 \mathrm{~d}$ in 1982.

Note again, however, that knot dates are poorly estimated at the start and end of these time series, and in 4 of 5 cases where the normal $\mathrm{Z} \rightarrow \mathrm{m} \rightarrow \mathrm{M}$ sequence is broken (denoted by negative numbers in Table 4), the discrepancy occurs early or late in the 5 yr record.

There is a consistent sequence from one category to the next for polychaetes, as the smoothed curves indicate that zooplanktonic peaks are always followed by meiofaunal peaks, then macrofaunal peaks of abundance (Fig. 3). The changes in abundance between categories, especially between meiofăunal and macrofaunal polychaetes, imply that macrobenthic polychaetes have higher rates of survival towards the end of the time series (Fig. 3). The apparent increase in abundance of both macrobenthic polychaetes ( $M$ in Fig. 3) since 1982 and macrobenthic bivalves ( $\mathrm{M}$ in Fig. 4) since 1983 has occurred even though there was no absolute change in the numbers of potential recruits to that size category. Comparing the average abundances seen over the 5 yr sampling period, there was a greater decrease between meiobenthic and macrobenthic bivalve abundance each year (Fig. 4) than between these same 2 categories of polychaetes (Fig. 3). 


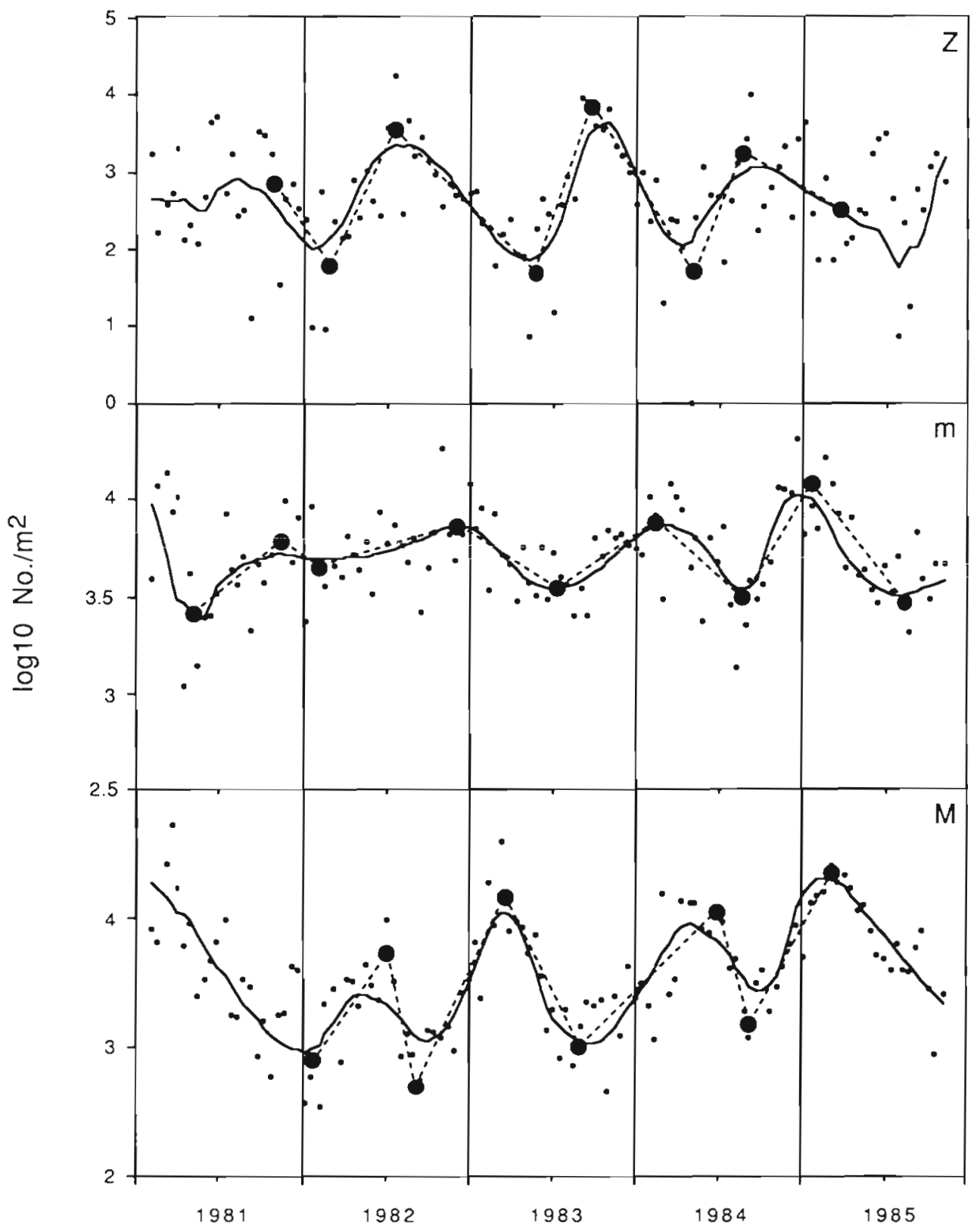

Fig. 3. $\log _{10}$ abundance (no. $\mathrm{m}^{-2}$ ) of zooplanktonic (Z), meiobenthic (m), and macrobenthic (M) polychaetes (plotted points). with fitted McDonaldOwen smooth (solid line) and spline (piecewise linear dashed line with knots) function

\section{DISCUSSION}

Questions posed in the 'Introduction' are readily answered with the quantitative analysis of these data sets. The polychaete and bivalve communities are reasonably predictable as to the timing of their appearance in the plankton, with peak abundance in the late summer or early fall for polychaete larvae and in the summer for bivalve larvae (Table 1). The meiofaunal polychaetes typically peak in the winter, with macrofaunal sized animals reaching maximum abundance in early spring. Meiofaunal bivalves are most abundant in late summer, and macrofauna in winter (Table 2). Peaks of abundance of the meiofaunal and macrofaunal categories of each taxon, with few exceptions, follow each other after the appearance of the planktonic larval pulse (Figs. $1 \& 2$; Table 4). The time intervals between successive peaks in abunclance of all 3 life-history categories, though variable, average about 1 yr for both the polychaetes and bivalves, implying physical control of this cyclic, nonchaotic, non-random recruitment pulse (Table 4). An annual cycle is further illustrated by the 1 yr average interval between successive minima within all 3 categories for both taxa, and agrees with the annual cycle measured for macrobenthic polychaetes using timeseries spectral analysis (see Coull 1986). A striking feature of polychaete and bivalve recruitment in 
Fig. 4. $\log _{10}$ abundance (no. $\mathrm{m}^{-2}$ ) of zooplanktonic (Z), meiobenthic $(\mathrm{m})$, and macrobenthic $(M)$ bivalves (plotted points), with fitted McDonaldOwen smooth (solid line) and spline (piecewise linear dashed line with knots) function

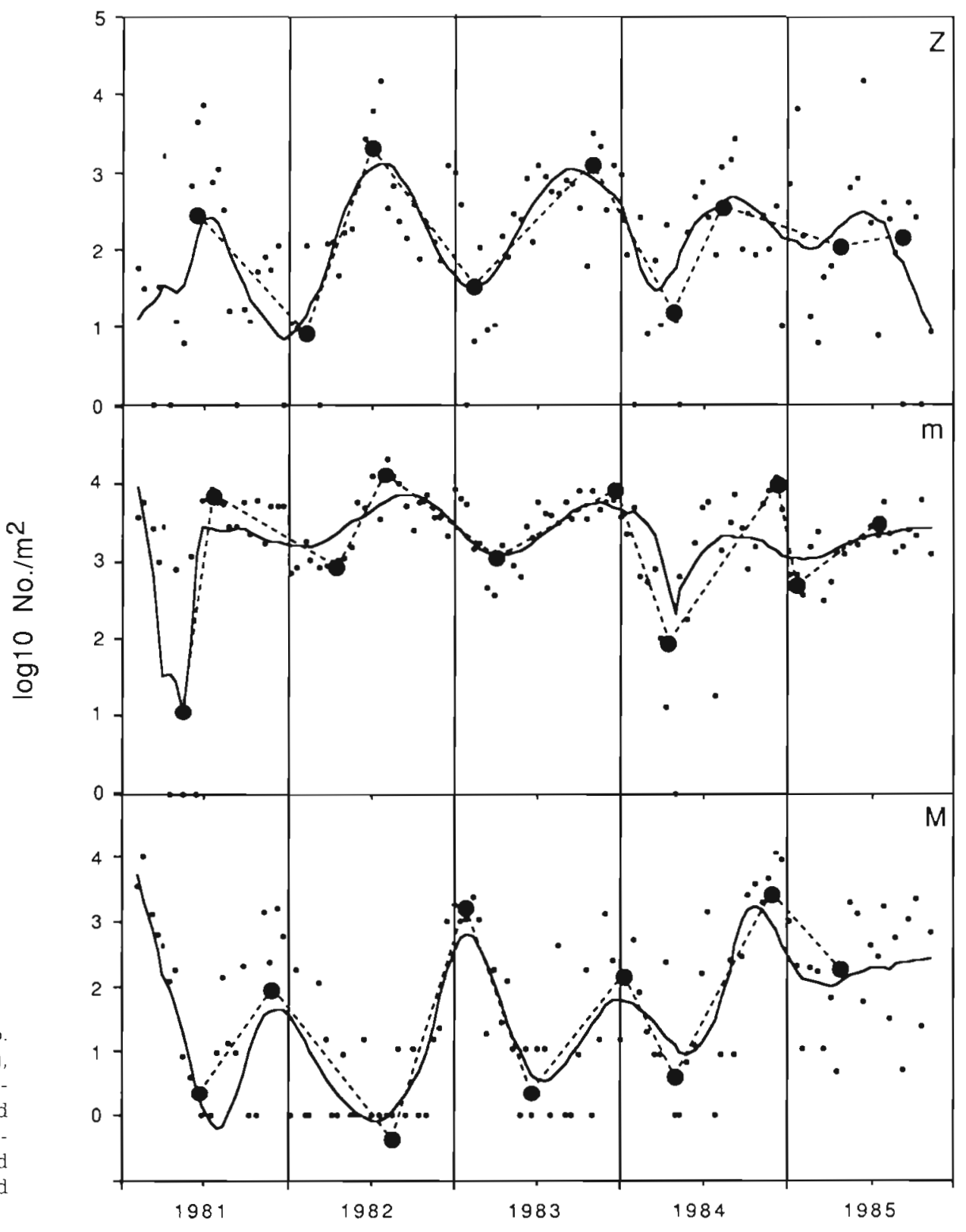

North Inlet was the much higher predictability of meiofaunal and macrofaunal peaks and minima of abundance compared with planktonic larval abundance peaks and minima (Table 4).

Questions concerning predictions of the magnitude of peak abundances are considerably more difficult to answer. The best correspondence between peak abundances of any 2 categories is between planktonic larval and meiofaunal categories $(\mathrm{Z} \rightarrow \mathrm{m})$, while correspondence between larval abundance and macrofaunal abundance $(Z \rightarrow M)$ and between meiofaunal and macrofaunal abundances $(m \rightarrow M$ ) is very poor (Table 1). Post-settlement events obviously impose a variable mortality on new arrivals to the bottom as they grow to macrofaunal size, lending support to the concept of the meiofaunal bottleneck espoused by Bell \& Coull (1980). Actual tests of the meiofaunal recruitment bottleneck hypothesis would be equivocal with our data - an experimental manipulative approach would be better.

Our measures of planktonic larval abundances are only snapshots of continually changing larval concentrations extrapolated to a unit area basis. Estimates of benthic abundances from core samples, however, represent cumulative settlement and loss over the previous 2 wk period. Certainly the greatest mortality must occur during the transition from a planktonic to a benthic existence, although our data show an 
Table 3. Values of $\mathrm{p}$ from tests of several null hypotheses regarding the quantitative analysis of abundance and its changes for the categories zooplanktonic larvae $(Z)$, meiobenthic juveniles $(m)$, and macrobenthos (M). Daily rates of change of abundance (g) refer to growth and decline phases between knots in Figs. $3 \& 4$. The hypotheses tested relate only to potential differences in parameters existing within a life-history category for each taxon separately

\begin{tabular}{|c|c|c|c|c|c|c|}
\hline \multirow[t]{2}{*}{ Null hypothesis } & \multicolumn{3}{|c|}{ Polychaetes } & \multicolumn{3}{|c|}{ Bivalves } \\
\hline & Z & $\mathrm{m}$ & M & Z & & M \\
\hline Minima occur at the same time of year each year & 0.210 & 0.005 & $<0.001$ & 0.248 & $<0.001$ & 0.051 \\
\hline Maxima occur at the same time of year each year & 0.131 & 0.556 & $<0.001$ & 0.019 & $<0.001$ & 0.331 \\
\hline Minimal abundances equal each year & 0.322 & 0.464 & 0.132 & 0.258 & $<0.001$ & $<0.001$ \\
\hline Maximal abundances equal each year & 0.023 & 0.142 & 0.011 & 0.231 & 0.654 & 0.014 \\
\hline All periods of increase are of equal duration & 0.890 & 0.748 & 0.007 & 0.195 & $<0.001$ & 0.803 \\
\hline All periods of decline are of equal duration & 0.033 & 0.810 & 0.039 & 0.632 & $<0.001$ & 0.121 \\
\hline All values of $g$ during periods of population increase are equal & 0.086 & 0.261 & 0.137 & 0.145 & 0.010 & 0.052 \\
\hline All values of $g$ during periods of population decline are equal & 0.181 & 0.365 & $<0.001$ & 0.394 & 0.286 & 0.193 \\
\hline
\end{tabular}

increase in organism abundance (Table 4). For example, polychaete larvae in September 1983 peaked at $6807 \mathrm{~m}^{-2}$ and appeared in the meiofauna at a density of $7496 \mathrm{~m}^{-2}$ in February 1984. The June 1984 macrobenthic polychaetes were even more abundant than the meiofaunal category (Table 4). There is simply too much variability to estimate mortality at this

Table 4. Number of days between successive peaks (knots) of abundance and between successive minima within and between categories for $(A)$ polychaetes and $(B)$ bivalves. $Z=$ planktonic larvae, $m=$ meiobenthic juveniles, $M=$ macrobenthos. Negative numbers denote a maximum or minimum that preceded rather than followed the otherwise next successive knot

\begin{tabular}{|c|c|c|}
\hline & $\begin{array}{c}\text { Intervals between } \\
\text { maxima }\end{array}$ & $\begin{array}{c}\text { Intervals between } \\
\text { minima }\end{array}$ \\
\hline \multicolumn{3}{|c|}{ A. Polychaetes } \\
\hline$Z \rightarrow Z$ & $\begin{array}{c}263,434,330 \\
(\operatorname{avg}=342 d)\end{array}$ & $\begin{array}{l}454,343,323 \\
(\operatorname{avg}=373 \mathrm{~d})\end{array}$ \\
\hline$Z \rightarrow m$ & $14,137,140,150$ & $-21,49,108,144$ \\
\hline $\mathrm{Z} \rightarrow \mathrm{M}$ & $245,241,275,196$ & $192,98,125$ \\
\hline $\mathrm{m} \rightarrow \mathrm{m}$ & $\begin{array}{c}386,437,340 \\
(\operatorname{avg}=387 d)\end{array}$ & $\begin{array}{c}272,524,402,359 \\
(\mathrm{avg}=389 \mathrm{~d})\end{array}$ \\
\hline $\mathrm{m} \rightarrow \mathrm{M}$ & $231,104,135,46$ & $259,213,49,17$ \\
\hline$M \rightarrow M$ & $\begin{array}{l}259,468,251 \\
(\operatorname{avg}=326 \mathrm{~d})\end{array}$ & $\begin{array}{c}226,360,370 \\
(\mathrm{avg}=319 \mathrm{~d})\end{array}$ \\
\hline \multicolumn{3}{|c|}{ B. Bivalves } \\
\hline$Z \rightarrow Z$ & $\begin{array}{c}386,486,284,393 \\
(\mathrm{avg}=387 \mathrm{~d})\end{array}$ & $\begin{array}{l}365,441,364 \\
(\operatorname{avg}=390 d)\end{array}$ \\
\hline$z \rightarrow m$ & $37,26,49,120,52$ & $64,53,-8,-96$ \\
\hline$Z \rightarrow M$ & $164,206,70,107$ & $191,136,5,-1$ \\
\hline $\mathrm{m} \rightarrow \mathrm{m}$ & $\begin{array}{c}375,509,355,221 \\
(a v g=365 d)\end{array}$ & $\begin{array}{c}334,354,380,276 \\
(\operatorname{avg}=336 \mathrm{~d})\end{array}$ \\
\hline$m \rightarrow M$ & $127,180,21,-13$ & $38,127,83,13,95$ \\
\hline$M \rightarrow M$ & $\begin{array}{l}428,350,321 \\
(\operatorname{avg}=366 \mathrm{~d})\end{array}$ & $\begin{array}{c}423,310,310,358 \\
(a \vee g=350 d)\end{array}$ \\
\hline
\end{tabular}

temporal scale, and we recommend that much more frequent samples be taken to accomplish this aim. Clearly, a biweekly sampling interval is much too long to pinpoint settlement or recruitment events with temporal precision.

The statistical methods employed here are still under development, but they have advanced our capabilities in the study of marine soft-bottom recruitment by allowing quantitative tests of hypotheses. The question remains whether the loss of biologically relevant details or patterns incurred by smoothing data on abundance is great enough to outweigh this singular, distinct advantage. We suggest that the evidence, exemplified by comparison of this study with the earlier qualitative paper of Stancyk \& Feller (1986), lies heavily in favor of the testable hypothesis approach used here.

These data are unique in several respects. Repetitive sampling at the same location with the same gear every $2 \mathrm{wk}$ is a rare occurrence in the literature on estuarine soft-bottom fauna. Many hard substrate studies have more frequent sampling intervals (e.g. daily; Wethey 1985, Young 1989), and many studies have been of much longer duration (e.g. over 2 decades; Ziegelmeier 1978), but none to our knowledge combine quantitative samples of all life-history phases (planktonic and 2 benthic) of the study organisms in soft-bottom habitats.

Many, but not all, macrobenthic polychaetes in this estuarine habitat have planktonic larvae (Wilson 1991). Hence excess recruitment from non-planktonic polychaete species could account for their increasing trend of abundance (Fig. 3). This is not likely, however, because the larval phase of nearly all $100+$ species of polychaetes in North Inlet includes at least some time in the plankton. Polychaetes which brood their larvae (e.g. some maldanids) or are facultative brooders (e.g. some spionids) are numerically scarce in the estuary. 
The numerically dominant spionid polychaete in North Inlet, Streblospio benedicti, is capable of brooding its young, but this reproductive mode is not common on the east coast of the USA (Levin 1984).

Finally, as noted by Green (1984), obtaining reliable estimates of baseline variation on the between-years time scale in recruitment of polychaetes and bivalves - or for any taxon in the marine environment - will require a considerably longer period of study than presented here. The few available long-term studies of recruitment variability among benthic taxa have found either that benthic-pelagic coupling is evident only at the broad levels of abundances or biomass (Austen et al. 1991) or that there is perhaps no coupling at all between events in the plankton and benthic populations (Roff et al. 1988). Based on a comparison between various meristic and life-history attributes of fish larvae and zooplankton, Skjoldal \& Melle (1989) predicted that, because zooplankton (and by extrapolation, zooplanktonic larvae) are less prone to mortality in the water column than fish larvae, one might expect much less variation from year to year in zooplanktonic larvae than in fish larvae. Even if this were true in a temporal sense for any given location, there would likely be great differences among locations. For instance, Wilson (1990) found heaviest settlement of bivalves in Bogue Sound, North Carolina, in late May and early June, compared to our highly variable and later peaks of bivalve larval abundance in North Inlet. We would predict that settlement will be equally variable from year to year in North Carolina, but it will require long-term sampling to settle the question.

Previously, Stancyk \& Feller (1986) reported a 4 to 6 mo lag between the appearance of peaks of abundance in planktonic bivalve larvae and the subsequent appearance of macrobenthic bivalves in North Inlet. Data for the intermediate size category, the meiobenthic bivalves, were not available in an appropriate form for estimating lags at the time that paper was written. However, lags between planktonic and benthic peaks measured with the quantitative statistical methods employed here ranged from 70 to $206 \mathrm{~d}$ ( 2.3 to $6.9 \mathrm{mo}$ ) for bivalves and from 196 to $245 \mathrm{~d}$ (6.5 to $8.1 \mathrm{mo}$ ) for polychaetes. Since the 1986 paper, we have reduced between-replicate sampling variability in the macrobenthos by increasing the number of cores from 2 to 8 per sampling date (with the same volume of sediment to process; see Michener et al. 1987 and Service \& Feller 1992). This has reduced the confidence intervals about estimates of abundance by about half for macrobenthic taxa. Between-replicate variance has been much lower for both zooplankton and meiobenthos which contain much larger numbers of individuals per sample than the macrobenthos.
The difficulties in quantitatively assessing coupling between different life-history phases of the pelagicbenthic invertebrate transition are enormous. We are convinced that the stock-recruitment problem - a lack of any predictable correspondence between levels of larval abundance in the plankton and subsequent adult abundance - is no less complex in benthic ecology than it is in fisheries ecology (Harris \& Griffiths 1987, Fogerty et al. 1991, Magnuson 1991).

To measure ecologically meaningful changes between tightly coupled planktonic and benthic phases (e.g. survivorship, settlement, predation losses) will require higher-frequency sampling (perhaps daily) within the same water mass with attendant increases in sample replication. Kenny et al. (1990) reached a similar conclusion regarding the study of mechanisms controlling oyster settlement and recruitment, pleading for even finer temporal scales of resolution - samples just minutes apart. The ideal situation (both longer and more frequent sampling) is probably unrealistic under most conditions. Simply increasing the length of our quantitative time series sampling effort to 10 or 15 yr will provide significantly more degrees of freedom for discriminating differences in recruitment events with these and other taxa. Identification of the time periods during which recruitment takes place each year in North Inlet increases the probability that future investigators can perform the requisite intensive sampling program at the correct times for species-level questions. Until now these temporal 'windows' have typically been unpredictable, especially for short-term studies. As our long-term data sets continue to grow in length, we can expect to define these windows with greater precision.

Acknowledgements. We thank the technical staff, especially L. Barker, R. McCutchen, G. Ogburn, and S. Service, and the Data Management group, especially S. Chapal, at the Baruch. Field Lab for their assistance in collecting these data. Data analysis and programming assistance were provided by $A$. Carter and R. Claus. Meiofaunal samples were sorted by B. Dudley. This research was supported by National Science Foundation grants DEB 8012165, BSR 85143326, and BSR 9011664 [F. J. Vernberg, principal investigator (PI), all authors Co-PIs], OCE 8007968,8308114 , and 8916255 (B. C. Coull, PI), with writing support from INT 8912528 (R. J. Feller, PI).

\section{LITERATURE CITED}

Austen, M. C., Buchanan, J B., Hunt, H. G., Josefson, A. B. Kendall, M. A. (1991). Comparison of long-term trends in benthic and pelagic communities of the North Sea. J. mar biol. Ass. U.K. 71: 179-190

Bell, S. 5., Coull, B. C. (1980). Experimental evidence for a model of juvenile macrofauna-meiofauna interactions. In Tenore, K. R., Coull, B. C. (eds.) Marine benthic dynamics Univ, South Carolina Press, Columbia, p. 179-192

Box, G. E. P., Cox, D. R. (1964). An analysis of transformations J. R. Statist. Soc. B26: 211-252 
Butman, C. A. (1987). Larval settlement of soft-sediment invertebrates: the spatial scales of pattern explained by active habitat selection and the emerging role of hydrodynamical processes. Oceanogr. mar. Biol. A. Rev. 25: $113-165$

Callahan, J. T (1984). Long-term ecological research. BioScience 34: 363-367

Connell, J. H. (1985). The consequences of variation in initial settlement vs. post-settlement mortality in rocky intertidal communities. J. exp. mar. Biol. Ecol. 93: 11-45

Coull, B. C. (1985). Long-term variability of estuarine meiobenthos: an 11 year study. Mar. Ecol. Prog. Ser. 24: 205-218

Coull, B. C. (1986). Long-term variability of meiobenthos: value, synopsis, hypothesis generation and predictive modelling. Hydrobiologia 142: 271-279

de Jonge, V. N., Bouwman, L. A. (1977). A simple density separation technique for quantitative isolation of meiobenthos using the colloidal silica gel Ludox-TM. Mar. Biol. 42: $143-148$

Fogerty, M. J., Sissenwine, M. P., Cohen, E. B. (1991). Recruitment variability and the dynamics of exploited marine populations. Trends Ecol. Evol. 6: 241-246

Franklin, J F., Bledsoe, C. S., Callahan, J. T. (1990). Contributions of the Long-Term Ecological Research Program. BioScience 40: 509-523

Gaines, S., Brown, S., Roughgarden, J. (1985). Spatial variation in larval concentrations as a cause of spatial variation in settlement for the barnacle, Balanus glandula Oecologia $67: 267-272$

Gallant, A. R. (1987). Nonlinear statistical models. John Wiley \& Sons, New York

Green, R. H. (1984). Statistical and nonstatistical considerations for environmental monitoring studies. Environ. Mon. Assessm. 4: 293-301

Hadfield, M. G. (1986). Settlement and recruitment of marine invertebrates: a perspective and some proposals. Bull. mar. Sci. 39: $418-425$

Harris, G. P. Griffiths, F. B. (1987). On means and variances in aquatic food chains and recruitment to the fisheries. Freshwat. Biol. 17: 381-386

Highsmith, R. C., Emlet, R. B. (1986). Delayed metamorphosis: effect on growth and survival of juvenile sand dollars (Echinoidea:Clypeastroidea). Bull. mar. Sci. 39: 347-361

Kenny, P. D., Michener, W. K., Allen, D. M. (1990). Spatial and temporal patterns of oyster settlement in a high salinity estuary. J. Shellfish Res. 9: 329-339

Kjerfve, B., Miranda, L. B., Wolanski, E. (1991). Modelling water circulation in an estuary and intertidal marsh system. Neth. J. Sea Res. 28: 141-147

Levin, L. A. (1984). Multiple patterns of development in Streblospio benedicti Webster (Spionidae) from three coasts of North America. Biol. Bull. 166: 494-508

Luckenbach, M. W. (1984). Settlement and early post-settlement survival in the recruitment of Mulinia lateralis (Bivalvia). Mar. Ecol. Prog. Ser 17: 245-250

Magnuson, J. J., Bowser, C. J. (1990). A network for long-term. ecological research in the United States. Freshwat. Biol. 23: $137-143$

Magnuson, J J. (1991). Fish and fisheries ecology. Ecol. Applic. 1.13-26

This artacle was presented by R. M. Warwick, Plymouth, UK
McDonald, J. A., Owen, A. B. (1986). Smoothing with split linear fits. Technometrics 28: 195-208

Michener, W. K., Feller, R. J., Edwards, D. G (1987). Development, management, and analysis of a long-term ecological research information base: example for marine benthos. In: Boyle, T. P. (ed.) New approaches to monitoring aquatic ecosystems. ASTM STP 940 , American Society for Testing and Materials, Philadelphia, p. $173-188$

Morse, A. N. C. (1991). How do planktonic larvae know where to settle? Am. Sci. 79: 154-167

Roff, J. C., Middlebrook, K., Evans, F. (1988). Long-term variability in North Sea zooplankton off the Northumberland coast: productivity of small copepods and analysis of trophic interactions. J. mar. biol. Ass. U.K. 68: 143-164

Roughgarden, J., Gaines, S., Possingham, H. (1988). Recruitment dynamics in complex life cycles. Science 241: $1460-1466$

SAS Institute Inc. (1985). SAS user's guide: statistics, Version 5 edn. SAS Institute, Cary, NC

Service, S. K., Feller, R. J. (1992). Long-term trends of subtidal macrobenthos in North Inlet, South Carolina. Hydrobiologia 231: 13-40

Skjoldal, H. R., Melle, W. (1989). Nekton and plankton: some comparative aspects of larval ecology and recruitment processes. Rapp. P.-v. Réun. Cons. int. Explor. Mer 191: $330-338$

Stancyk, S. E., Feller, R. J. (1986). Transport of non-decapod invertebrate larvae in estuaries: an overview. Bull. mar. Sci. 39: $257-268$

Strathmann, R. R., Branscomb, E. S. (1979). Adequacy of cues to favorable sites used by settling larvae of two intertidal barnacles. In: Stancyk, S. E. (ed.) Reproductive ecology of marine invertebrates. Univ. South Carolina Press, Columbia, p. 77-89

Wahba, G. (1990). Spline functions for observational data. CBMS-NSF Regional Conference Series. Society for Industrial and Applied Mathematics, Philadelphia

Wethey, D. S. (1985). Local and regional variation in settlement and survival in the littoral barnacle Semibalanus balanoides (L.): patterns and consequences. In: Seed, R., Moore, P. G. (eds.) The ecology of rocky coasts. Hodder \& Stoughton, Sevenoaks, p. 194-202

Wilson, F. S. (1990). Temporal and spatial patterns of settlement: a field study of molluscs in Bogue Sound, North Carolina. J. exp. mar. Biol. Ecol. 139: 201-220

Wilson, W. H. (1991). Sexual reproductive modes in polychaetes: classification and diversity. Bull. mar. Sci. 48: $500-516$

Woodin, S. A. (1986). Settlement of infauna: larval choice? Bull. mar. Sci. 39: 401-407

Yoshioka, P. M. (1986). Chaos and recruitment in the bryozoan, Membranipora membranacea. Bull. mar. Sci. 39: 408-417

Young, B. L. (1989). Settlement, early mortality, and growth of sessile marine invertebrates. Ph.D. dissertation, Univ. of South Carolina, Columbia

Ziegelmeier, E. (1978). Macrobenthic investigations in the Eastern part of the German Bight from 1950-1974. Rapp. P.-v. Réun. Cons. int. Explor. Mer 172: 432-444

Manuscript first received: October 25, 1991

Revised version accepted: August 27, 1992 